\title{
AA. VV., Les méditations cosmographiques à la Renaissance, sous la direction de Frank Lestringant
}

\section{Michele Mastroianni}

\section{(2) OpenEdition}

\section{Journals}

\section{Edizione digitale}

URL: http://journals.openedition.org/studifrancesi/6595

DOI: 10.4000/studifrancesi.6595

ISSN: 2421-5856

\section{Editore}

Rosenberg \& Sellier

\section{Edizione cartacea}

Data di pubblicazione: 1 septembre 2010

Paginazione: 352-353

ISSN: 0039-2944

\section{Notizia bibliografica digitale}

Michele Mastroianni, «AA. VV., Les méditations cosmographiques à la Renaissance, sous la direction de Frank Lestringant», Studi Francesi [Online], 161 (LIV | II) | 2010, online dal 30 novembre 2015, consultato il 07 janvier 2021. URL: http://journals.openedition.org/studifrancesi/6595 ; DOI: https:// doi.org/ERREUR PDO dans /localdata/www-bin/Core/Core/Db/Db.class.php L.34 : SQLSTATE[HY000] [2006] MySQL server has gone away

Questo documento è stato generato automaticamente il 7 janvier 2021.

\section{cc) (†) $\odot$}

Studi Francesi è distribuita con Licenza Creative Commons Attribuzione - Non commerciale - Non opere derivate 4.0 Internazionale. 


\title{
AA. VV., Les méditations cosmographiques à la Renaissance, sous la direction de Frank Lestringant
}

\author{
Michele Mastroianni
}

\section{NOTIZIA}

AA. VV., Les méditations cosmographiques à la Renaissance, sous la direction de Frank LESTRINGANT, Paris, PUPS, 2009 («Cahiers V.L. Saulnier», 26), pp. 220.

1 Come il curatore sottolinea in apertura (Frank LESTRINGANT, La Méditation cosmographique, une méditation entre deux livres, pp. 7-16) questo Cahier si riallaccia a quasi vent'anni di distanza al Cahier Saulnier $n^{\circ} 7$ consacrato a La Méditation en prose à la Renaissance, riprendendo appunto il tema della méditation, intesa come riflessione volta a mettere in pratica i contenuti dell'apprendimento, applicata questa volta a una scienza cosmografica che non è soltanto descrizione ma interpretazione del cosmo.

I saggi qui contenuti sono i seguenti: Patrick GAUTIER DALCHÉ, Pour une histoire des rapports entre contemplation et cartographie au Moyen Âge (pp. 19-40), Giorgio MANGANI, Des villes pour prier. De la ville méditative au projet d'architecture (pp. 41-55), Angelo CATTANEO, Cosmographie et prédication médiévale et renaissante (pp. 57-70), Isabelle PANTIN, 'Altius incubuit animus sub imagine mundi'. L'inspiration du cosmographe d'après une gravure d'Oronce Finé (pp. 73-94), Tom CONLEY, Le méditer: via Apian (pp. 95-112), Thibaut MAUS DE ROLLEY, Le globe et le chevalier: variations sur la méditation cosmographique dans la fiction chevaleresque de la Renaissance (pp. 113-140), Jörg DÜNNE, Méditation, médialité, subjectivité: $d u$ 'regard d'en haut' au panoptisme cartographique (pp. 143-156), Georges TOLIAS, Glose, contemplation, et méditation. Histoire éditoriale et fonctions du «Parergon» d'Abraham Ortelius 
(pp. 157-186), Marie-Dominique couZINET, Note sur les méditations cosmographiques et le pédantisme chez Montaigne (pp. 187-196).

3 Così Frank Lestringant enuclea il significato di méditation cosmographique. "Tra i diversi generi di meditazione, egli afferma, la meditazione cosmografica presenta una particolarità del tutto notevole. Se la meditazione in generale suppone la presenza prima di un libro, che per i cristiani è la Bibbia, la meditazione cosmografica implica per parte sua la coesistenza di due libri, la Sacra Scrittura e il libro del mondo. La meditazione cosmografica sarebbe la messa in relazione di questi due libri, il movimento di viavai dal primo al secondo libro, dal libro delle creature alla parola di Dio, e viceversa. [...] I due libri, il libro della natura o libro del mondo, e il libro sacro, la Scrittura, sono inseparabili l'uno dall'altro, a dispetto di quanto affermava il teologo catalano Raimond Sebond in apertura della sua Théologie naturelle ou livre des créatures tradotta in francese da Montaigne» (p. 8). Ora i contributi qui riuniti si pongono in questa prospettiva, quella appunto di chiarire come la lettura della carta del mondo possa costituire in certo qual modo un esercizio spirituale. 